\title{
Characterization and components separation of corn stover by alkali and hydrogen peroxide treatments
}

\author{
Li Cong, Zhang Li, Zhang Guanqun, Xu Jianguo, Zhang Long* \\ Changchun University of Technology, Jilin Provincial Engineering Laboratory for the Complex Utilization of Petroresources \\ and Biomass, Changchun, 130012. P. R. China \\ *Corresponding author: e-mail: zhanglongzhl@163.com
}

\begin{abstract}
The dissolution of corn stover in alkaline solvent system composed of $\mathrm{NaOH}-\mathrm{H}_{2} \mathrm{O}_{2}$ was reported and the separation of its ingredients combined with acid precipitation, ethanol extraction was proposed. It is proven that the residual after alkali solvent was cellulose, the filtrate by the acid precipitation of the liquor was lignin, the solid by the ethanol extraction of the liquor was hemicellulose. The optimum dissolution conditions were determined by single-factor experiment as follows: the concentration of $\mathrm{H}_{2} \mathrm{O}_{2} 5.0 \%, \mathrm{pH} 11.5$, dissolution temperature $60^{\circ} \mathrm{C}$, dissolution time $3.0 \mathrm{~h}$, the ratio of liquid to solid $30 \mathrm{~mL} / \mathrm{g}$. And chemical analysis were employed to determine the purity of the components separated. The structure of the components separated were identified by FT-IR, SEM, XRD and NMR. The cellulose recovery yield can achieve to $84.2 \%$ and lignin recovery yield is $86.6 \%$, the hemicellulose recovery yield is $96.7 \%$. After recycling the solvent 3 times, the recovery yield of cellulose, lignin and hemicellulose were 82.7, 87.6 and 97.4\%, and the purity of cellulose, lignin and hemicellulose were 98.0, 96.5 and $98.7 \%$, respectively.
\end{abstract}

Keywords: Corn stover, Lignin, Hemicellulose, Cellulose, Component separation, $\mathrm{NaOH}-\mathrm{H}_{2} \mathrm{O}_{2}$.

\section{INTRODUCTION}

Corn stover is a kind of abundant lignocellulosic biomass renewable on earth especially in China. As we attempt to reduce its adverse impact on the environment and to use it to produce various chemicals, the development of effective technologies for the efficient utilization of corn stover is considered to be both important and of practical value ${ }^{\mathbf{1}, 2}$.

The corn stover is a complex natural biopolymer that composed of three main components which including lignin, hemicelluloses and cellulose. Crystalline microfibrils of cellulose are surrounded by amorphous hemicellulose and the whole is embedded in the matrix of lignin. Cellulose is the most abundant component in lignocellulosic structure, consisting of a linear polymer of $\beta-1.4$ linked glucose units ${ }^{3}$. And associated with hemicellulose, which is a branched polymer composed of sugars such as pentoses and hexoses. Lignin occurs throughout the plant cell-wall and is mainly concentrated in the middle lamella and the primary cell-wall. This polymer is mostly formed by phenylpropane units, which makes it a highly complex and recalcitrant compound. The composition and percentages of cellulose, hemicelluloses and lignin vary depending on the plant species, ${ }^{4,5}$, and their differences in chemical structure give them different chemical reactivities. Pretreatment is an essential step in the conversion of lignocellulosic substrates, many pretreatment processes are under investigation at present, such as acid treatment, alkali treatment ${ }^{6}$ and steam explosion ${ }^{7}$. Tae Hyun $\mathrm{Kim}^{8}$ reported the fractionation of corn stover with hot-water and aqueous ammonia treatment. With proper operation the yield of lignin removal was $75.0-81.1 \%$. The remaining solid contained $78-85 \%$ cellulose. Sun ${ }^{9}$ and coworkers report that a combined process of wheat straw steam-exploded and sequential alkaline peroxide post-treatment with recovery of lignin being 92.4-99.4\% of the original lignin from wheat straw, but the separation of other components is not mentioned. The recovery yield of hemicellulose is $80 \%$. Lignin separation and fractionation by ultrafiltration is researched by A. Toledano and his coworkers ${ }^{\mathbf{1 0}}$. However, none of them are entirely satisfactory in regard to effectiveness, cost and environmental impacts. Therefore, a new method for the components separation of corn stover is proposed is of great practical value.

The components separation of corn stover in $\mathrm{NaOH}-$ $-\mathrm{H}_{2} \mathrm{O}_{2}$ system was reported by this paper. And in this study, broad range of reaction and operating conditions were explored to seek the optimal range of the process parameters that allowed satisfactory fractionation of corn stover.

\section{EXPERIMENTAL}

\section{Material \\ Corn stover was obtained from Changchun. The initial composition of corn stover as determined by NREL was as follows: cellulose, hemicellulose, lignin, ash, wax are 37.5, 25.4, 17.6, 14.4 and 5.1\%, respectively. Sodium hy- droxide, $\mathrm{H}_{2} \mathrm{O}_{2}(\varphi=30 \%)$, hydrochloric acid $(\varphi=18.3 \%)$, ethanol $(98.0 \%)$ were of analytical grade and purchased from Tianjin Guangfu Technology Development Co. Ltd.}

\section{Alkaline peroxide treatment and component separation process}

Samples of dewaxed corn stover was treated with alkaline peroxide solution. Upon completion, the solid was collected through vacuum filtration and the suspension was adjusted to $\mathrm{pH} 2.0$ with $\mathrm{HCl}(\varphi=18.3 \%)$, then a large mount of fine precipitate was produced, collected the solid by centrifugation. The rest of the filtrate was concentrated in vacuo to $1 / 10$ of the original volume, adjusting $\mathrm{pH}$ to 11.5 with $\mathrm{NaOH}(0.1 \mathrm{M})$ and adding three volumes of $98 \%$ ethanol to the filtrate, the insoluble residue was collected by centrifugation. Recovered ethanol by distilling the filter after ethanol extraction and the rest of the filtrate can be used in the recycling experiments. 


\section{Measurements and analytic methods}

Chemical analysis was employed to determine the purity of the components separated, the structure of the components separated were identified by FT-IR, SEM, XRD and NMR.

\section{CP/MAS ${ }^{13} \mathrm{C}$ NMR analysis}

The NMR spectra were acquired with a Bruker AV 500 spectrometer (Bruker company, Switzerland) for ${ }^{13} \mathrm{C}$ NMR at $60^{\circ}$. The scan number was up to 10.000 .

\section{FT-IR analysis}

The raw as well as corn straw steam exploded and chemically treated were analyzed as $\mathrm{KBr}$ pellets using a FT04-035 FT-IR spectrometer (Thermo Technology Co., LTD, USA) at room temperature. All spectra were recorded with an accumulation number of 32 scans and a resolution of $4 \mathrm{~cm}^{-1}$ in the range from 4000 to $400 \mathrm{~cm}^{-1}$.

\section{X-Ray diffractometry analysis}

XRD patterns were obtained on a Philips X'Pert Pro X-ray diffractometer using $\mathrm{CuKa}$ radiation (Philips company, Netherlands). The XRD patterns with $\mathrm{Cu} K \alpha$ at $40 \mathrm{kV}$ and $30 \mathrm{~mA}$ were recorded in the region of $2 \theta$ from 5 to $40^{\circ}$.

\section{SEM analysis}

The SEM micrographs were taken on a JSM-6480LV scanning electron microscope (JEOL technology co., LTD, Japan). The samples were glued to the sample stage and were sputtered with gold, then observed the fracture surface and photographed.

\section{Determination of the purity of the components separated}

The purity of the components were determined according to the methods described by Pan $^{11}$.

\section{Recovery yield of components in corn stover}

The recovery yield of lignin, cellulose and hemicellulose corresponding to $\omega_{1}, \omega_{2}$ and $\omega_{3}$ were calculated from following equation, respectively.

$\omega_{1}=\frac{m_{1}-m_{2}}{m_{0} \times \omega_{1}^{\prime}} \times 100 \%$

$\omega_{2}=\frac{m_{3}}{m_{0} \times \omega_{2}^{\prime}} \times 100 \%$

$\omega_{3}=\frac{m_{4}}{m_{0} \times \omega_{3}^{\prime}} \times 100 \%$

Where $m_{0}$ is the mass of corn stover added before dissolution, $m_{1}, m_{2}$ and $m_{3}$ are the mass of solid residual after dissolution, ash of corn stover, lignin precipitate after acid precipitation and hemicellulose extracted by ethanol, and $\omega_{1}^{\prime}, \omega^{\prime}{ }_{2}$ and $\omega^{\prime}{ }_{3}$ are the percentage of the lignin, cellulose and hemicellulose in corn stover, respectively.

\section{Component Separation Principle}

$\mathrm{H}_{2} \mathrm{O}_{2}$ can be decomposed into $\mathrm{OH}$ radicals and superoxide anion radicals $\mathrm{O}^{2-}$. under alkaline media, which are thought to cause the oxidation of lignin structures leading to the formation of hydrophilic (carboxyl) groups to cleave the interunit bonds between lignin and hemicelluloses, and eventually lignin and hemicellulose dissolved in alkali media, resulting the separation of cellulose from it, lignin and hemicellulose in the filtrate can be separated following acid precipitation and ethanol extraction. Scheme for component separation of corn stover is shown in Figure 1.

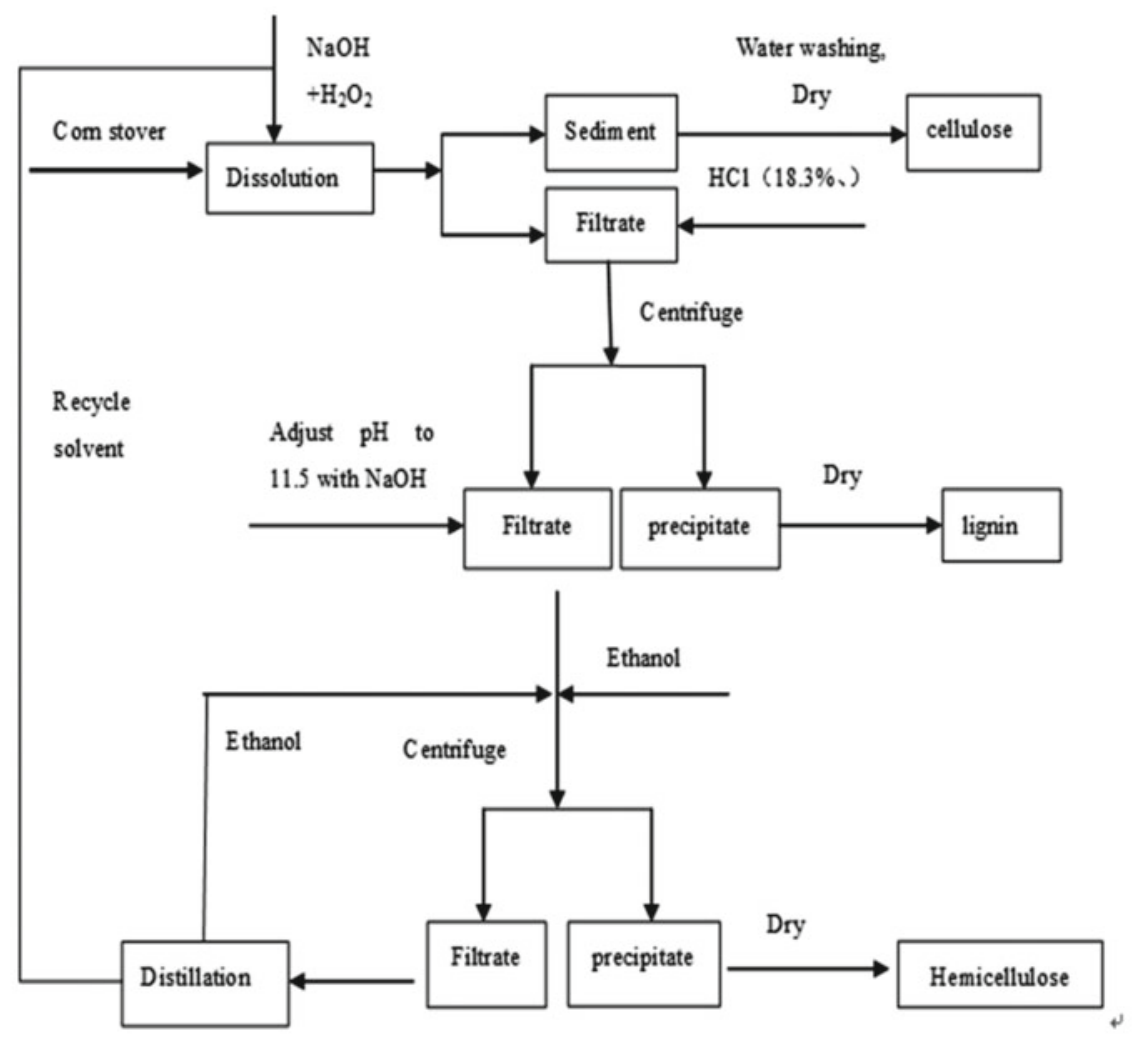

Figure 1. Scheme for dissolution and component separation of corn stover 


\section{RESULTS AND DISCUSSIONS}

\section{Dissolution temperature}

The effect of dissolution temperature on lignin, cellulose and hemicellulose recovery yield of corn stover were shown in Figure 2. It shows that the recovery yield of three components increased with increasing dissolution temperature, for the rate of saponification of intermolecular ester bonds cross-linking the lignin and hemicellulose increased, then they reach a plateau when the temperature was above $60^{\circ}$, due to the complete dissolution of lignin and hemicellulose. So $60^{\circ}$ was selected to be the optimal dissolution temperature.

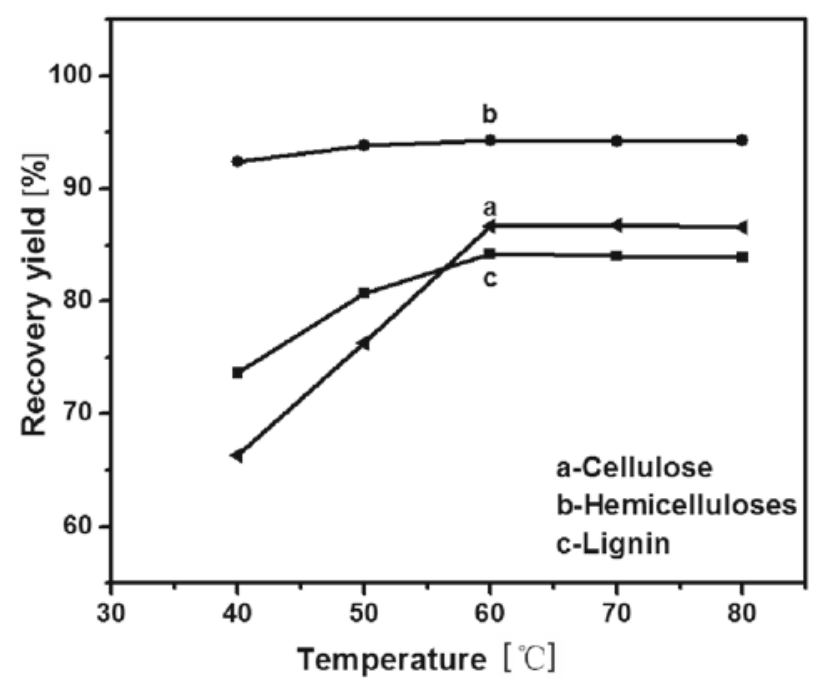

Figure 2. Effect of dissolution temperature on lignin, cellulose and hemicellulose recovery yield of corn stover $(\mathrm{pH}$ 11.5, ratio of liquid to solid 20:1, dissolution time $3.0 \mathrm{~h}$, $\mathrm{H}_{2} \mathrm{O}_{2}$ concentration $3.0 \%$ )

\section{Dissolution time}

The effect of dissolution time on lignin, cellulose and hemicellulose recovery yield in corn stover was similar to that of temperature (Fig. 3). With increasing the dissolution time, the recovery yield of lignin, cellulose and hemicellulose rapidly increased. Then it reached a plateau at $3.0 \mathrm{~h}$, further dissolution of lignin and hemicellulose were not observed. Higher solubility of hemicelluloses and lignin was presumed to be due to the fast cleavage of the ester bonds between hydroxycinnamic acids, such as p-coumaric and ferulic acids and hemicelluloses or lignin, and theta-benzyl ether linkages between lignin and hemicelluloses from the cell walls of corn stover by alkali. So $3.0 \mathrm{~h}$ was selected to be the optimal dissolution time.

\section{Ratio of liquid to solid}

The effect of liquid to solid ratio on lignin, cellulose and hemicellulose recovery yield of corn stover were shown in Figure 4. The recovery yield of three components increased significantly with increasing liquid to solid ratio and almost kept unchanged when the ratio reached to or above $30 \mathrm{~mL} / \mathrm{g}$. Therefore the liquid to solid molar ratio was controlled at 30:1.

\section{Solution pH}

Figure 5 shows the effect of solution $\mathrm{pH}$ on lignin, cellulose and hemicellulose recovery yield of corn stover.

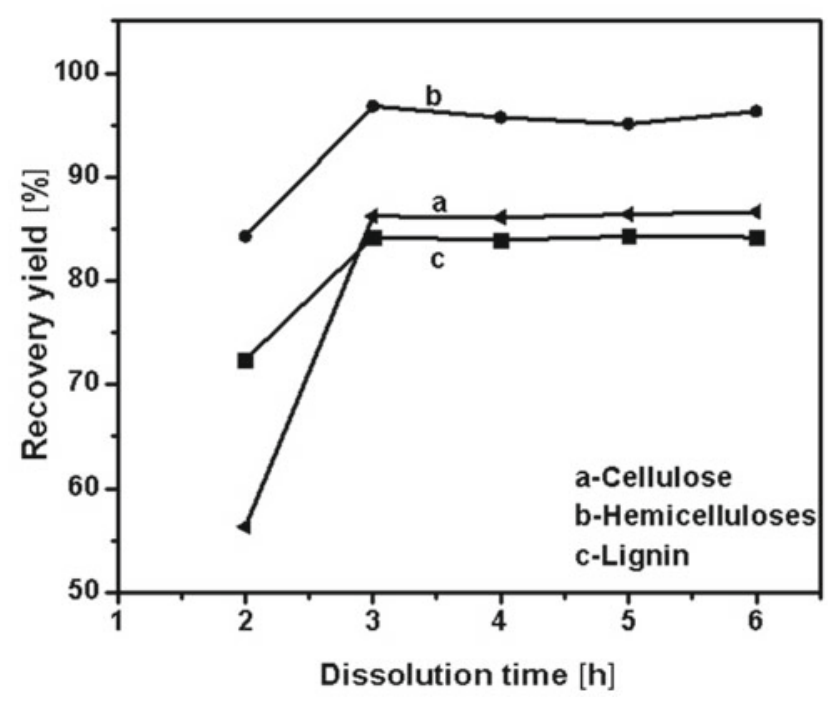

Figure 3. Effect of dissolution time on lignin, cellulose and hemicellulose recovery yield of corn stover $(\mathrm{pH} 11.5$, ratio of liquid to solid 20:1, dissolution temperature $60^{\circ} \mathrm{C}, \mathrm{H}_{2} \mathrm{O}_{2}$ concentration $3.0 \%$ )

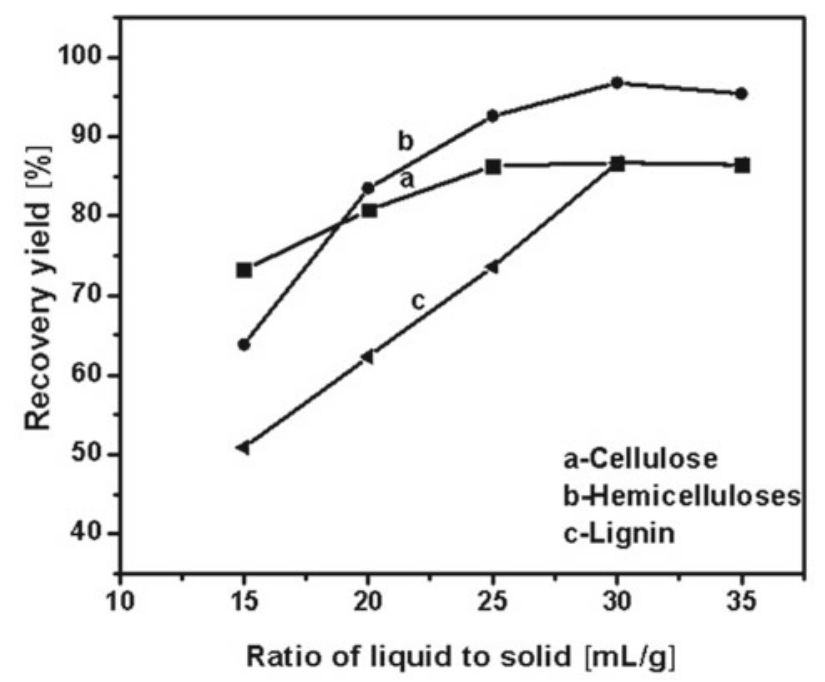

Figure 4. Effect of ratio of liquid to soid on lignin, cellulose and hemicellulose recovery yield of corn stover $(\mathrm{pH} 11.5$, dissolution temperature $60^{\circ} \mathrm{C}$, dissolution time 3.0 , $\mathrm{H}_{2} \mathrm{O}_{2}$ concentration $3.0 \%$ )

The delignification and hemicellulose solubilization catalyzed by $\mathrm{H}_{2} \mathrm{O}_{2}$ strongly depended on the solution $\mathrm{pH}$, the total alkalinity of the solution should be high enough to ensure an adequate concentration of hydroperoxide anion $\left(\mathrm{HOO}^{-}\right)$. On the other way, when the alkalinity is high enough to decompose the peroxide, the reactive hydroxyl radicals (HO·) and superoxide anion radicals $\left(\mathrm{O}_{2}^{-} \cdot\right)$ are formed ${ }^{\mathbf{1 2}}$, these radicals may react further with each other and to form oxygen and hydroxyl anions as the final products, leading to an increase in the solution $\mathrm{pH}^{\mathbf{1 3}}$ and accelerate the dissolution of lignin and hemicellulose. Therefor the optimal $\mathrm{pH}$ is choosen as $\mathrm{pH}=11.5$.

$\mathrm{H}_{2} \mathrm{O}_{2}+\mathrm{HO}^{-} \longleftrightarrow \mathrm{HOO}^{-}+\mathrm{H}_{2} \mathrm{O}$

$\mathrm{H}_{2} \mathrm{O}_{2}+\mathrm{HOO}^{-} \longrightarrow \mathrm{HO} \cdot+\mathrm{O}_{2}^{-}+\mathrm{H}_{2} \mathrm{O}$

$\mathrm{HO}+\mathrm{O}_{2}^{-} \longrightarrow \mathrm{O}_{2}+\mathrm{HO}^{-}$ 


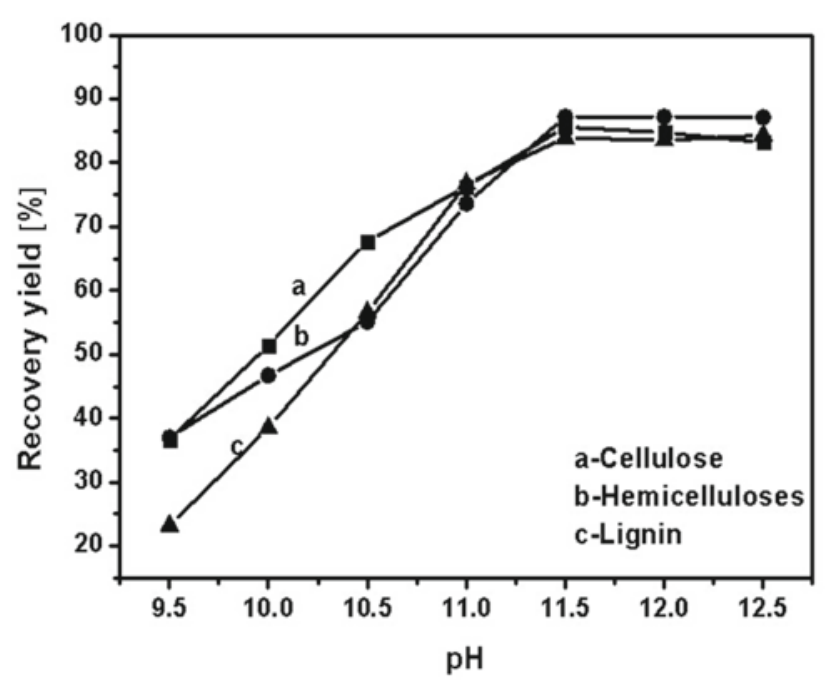

Figure 5. Effect of solution $\mathrm{pH}$ on lignin, cellulose and hemicellulose recovery yield of corn stover(ratio of liquid to solid 20:1, dissolution temperature $60^{\circ} \mathrm{C}$, dissolution time $3.0 \mathrm{~h}, \mathrm{H}_{2} \mathrm{O}_{2}$ concentration $3.0 \%$ )

\section{$\mathrm{H}_{2} \mathrm{O}_{2}$ concentration}

$\mathrm{H}_{2} \mathrm{O}_{2}$ concentration is one of the key factor influencing the lignin, cellulose and hemicellulose recovery yield of corn stover. As can be seen from Figure 6, the recovery of lignin and hemicellulose increased when $\mathrm{H}_{2} \mathrm{O}_{2}$ concentration changed from $2.0 \%$ to $7.0 \%, \mathrm{H}_{2} \mathrm{O}_{2}$ concentration played a key role to break intra-moleculae and intermolecular hydrogen bond of cellulose and the intramolecular hydrogen bond of polysaccharides. According to literature ${ }^{\mathbf{1 4}}$, the concentration of $\mathrm{H}_{2} \mathrm{O}_{2}$ has to be used as low as possible in order to prevent the degradation of cellulose components, $5.0 \% \mathrm{H}_{2} \mathrm{O}_{2}$ is used for the further separation experiment.

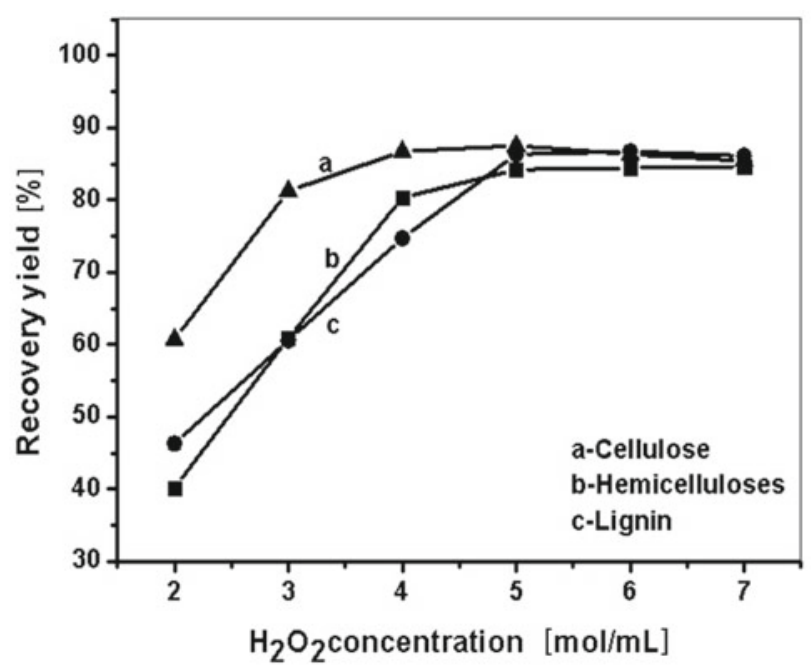

Figure 6. Effect of $\mathrm{H}_{2} \mathrm{O}_{2}$ concentration on lignin, cellulose and hemicellulose recovery yield in corn stover (ratio of liquid to solid 20:1, dissolution temperature $60^{\circ} \mathrm{C}$, dissolution time $3.0 \mathrm{~h}, \mathrm{pH} 11.5$ )

\section{Solvent recycling experiments}

Recovered the ethanol from the filtrate and add $30 \%$ $\mathrm{H}_{2} \mathrm{O}_{2}$ to the filtrate remained until the $\mathrm{H}_{2} \mathrm{O}_{2}$ concentration of it was $5.0 \%$, adjust its $\mathrm{pH}$ to 11.5 by $\mathrm{NaOH}$ solution, then it is used to dissolve and separate the corn stover. The results After 3 times recycling are shown in Figure 7.

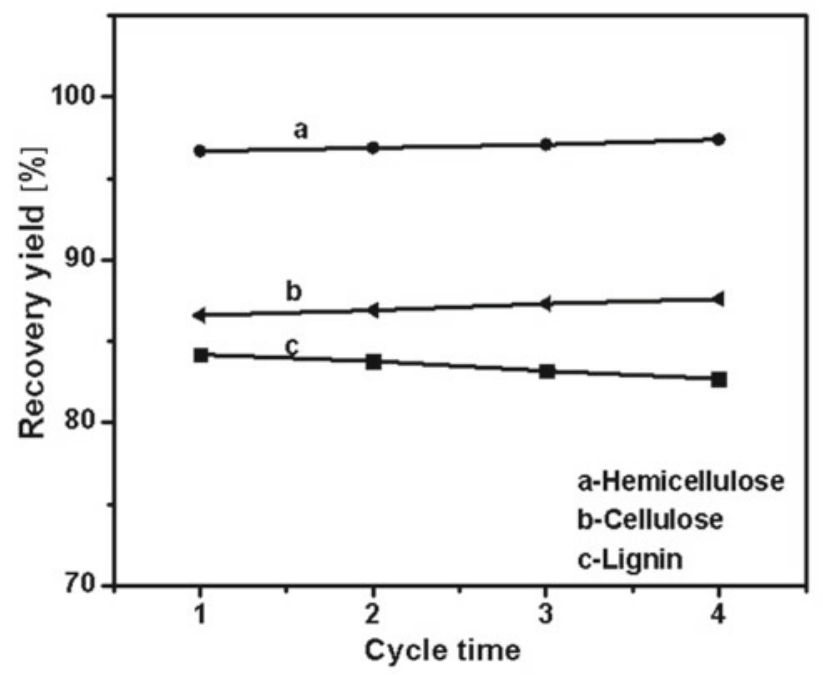

Figure 7. Effect of cycle times on lignin, cellulose and hemicellulose recovery yield of corn stover (ratio of liquid to solid 30:1, dissolution temperature $60^{\circ} \mathrm{C}$, dissolution time $3.0 \mathrm{~h}$ )

It can be seen from Figure 7, after recycling the filtrate, lignin and hemicellulose cellulose recovery yield increased slightly, it is proven that the solvent recycling experiments is feasible.

As shown in the experiment above, the optimal dissolution conditions were determined by single-factor experiment as follows: the liquid-solid ratio 30:1; dissolution temperature was $60^{\circ} \mathrm{C}$; dissolution time was $3.0 \mathrm{~h}$; $\mathrm{pH}$ was 11.5; $\mathrm{H}_{2} \mathrm{O}_{2}$ concentration was $5.0 \%$. At this condition, the lignin, cellulose and hemicellulose recovery yield was 86.6, 84.2 and $96.7 \%$, respectively. After recycling the solvent 3 times, the lignin, cellulose and hemicellulose recovery yield was $87.6,82.7$ and $97.4 \%$, respectively

\section{Structure and purity analysis of components separated CP/MAS ${ }^{13} \mathrm{C}$ NMR analysis}

The CP/MAS ${ }^{13} \mathrm{C}$ NMR spectra of the corn stover, lignin, cellulose and hemicellulose are separated shown in Figure 8. As shown in the Figure 8b, the resonances of cellulose occur at $105.0 \mathrm{ppm}$ for $\mathrm{C}-1$, at 83.6 and 88.2 ppm for C-4, and at $64.2 \mathrm{ppm}$ for C-6. The resonances of C-2, C-3 and C-5 overlap each other and appear at 73.4 ppm. In more detail, the peak at $88.2 \mathrm{ppm}$ is assigned to crystalline cellulose and at $83.6 \mathrm{ppm}$ to disordered cellulose. According to reports in the literature ${ }^{\mathbf{1 5}}$, The signal at $d=88.2$ resulted from the vibration of crystal cellulose, the weak signal at $d=135.8$ and 153.3 is the lignin that inset in the cellulose.

The signal of xylan appeared at $d=102.5$ and 62.1 . In Figure 8c, the signal at $\delta 102.5$ (C1) of $\beta$-D-xylose units and the signal at $\delta 62.1$ are characteristic C5 of the $\alpha$-L- arabinofuranosyl residues that are $(1 \rightarrow 3)$-linked to the $\beta$-D-xylans, therefore, it could be deduced that the residual after ethanol extraction is hemicellulose, which is mainly composed of most xylose and a small amount of arabinose, resonance peak overlap of hemicelluloses of C2, C3, C5 was detectable at $d=72.7$ and $d=72.2$. As can be seen in Figure 8d, the signal at 55.7, 61.0, 153.9 and 115.9 is lignin, $d=172.5$ and $d=24.6$, it could be concluded that acetylation was happened after treatment by alkali system. 

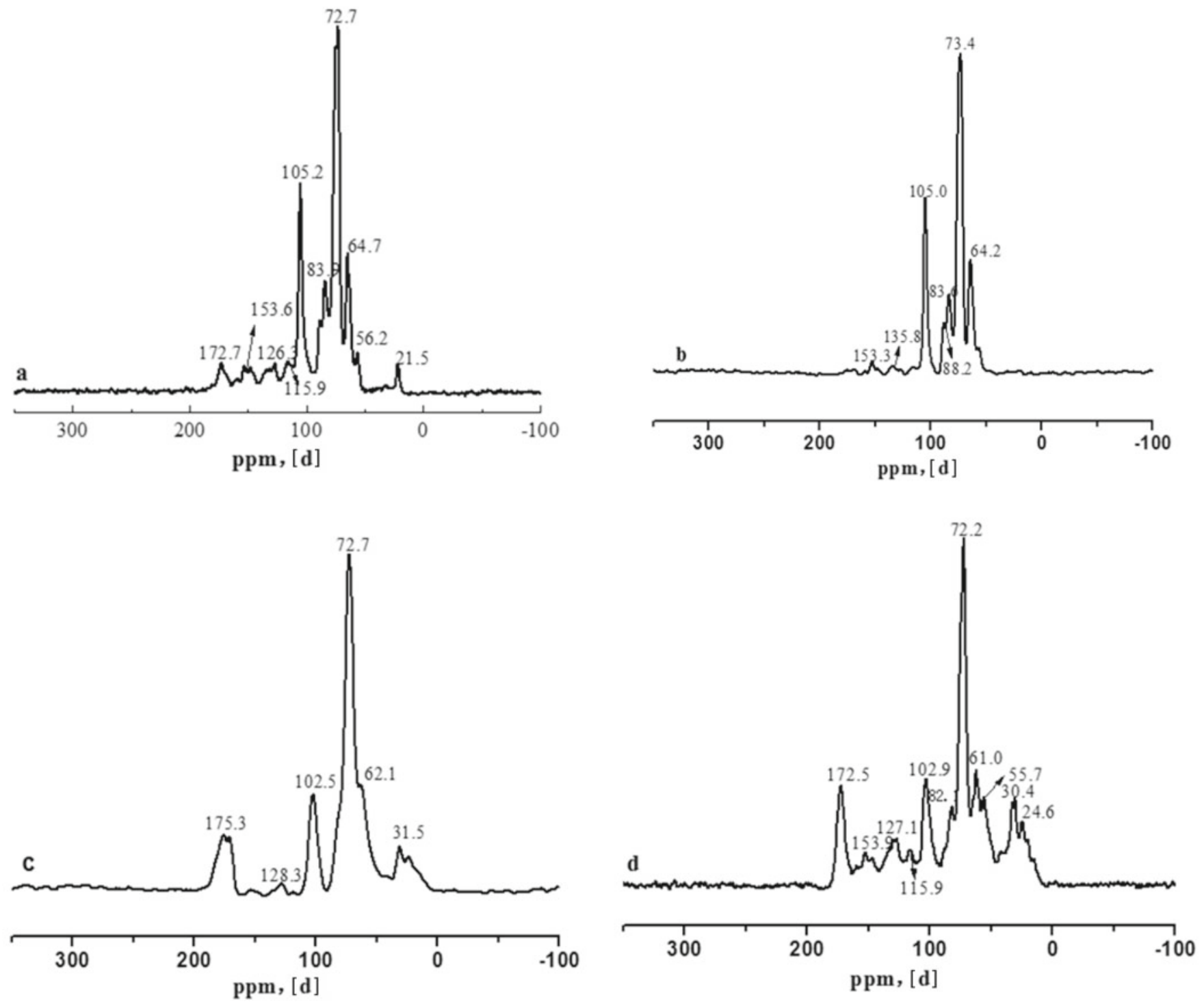

Figure 8. The 13C NMR spectrum of: (a) corn stover, (b) cellulose, (c) hemicelluloses, (d) lignin

\section{FT-IR analysis}

Figure 9 shows the IR spectra of corn stover, cellulose hemicelluloses and lignin. The band at $1170 \mathrm{~cm}^{-1}$ in the curve $b$ which is indicative of cellulose. The peaks in area $3450 \mathrm{~cm}^{-1}$ correspond to $\mathrm{O}-\mathrm{H}$ stretching band, that is, due to vibrations of the hydrogen bonded hydroxyl group ${ }^{16,17}$, the peaks at $2920 \mathrm{~cm}^{-1}$ are due to the aliphatic saturated $\mathrm{C}-\mathrm{H}$ stretching vibration in lignin polysaccharides (cellulose and hemicelluloses).

In the curve $c$, it had a specific band maximum at $1049 \mathrm{~cm}^{-1}$, typical of xylans. While xylan is the main component of hemicelluloses and this region is dominated by ring vibrations overlapped with stretching vibrations of $(\mathrm{C}-\mathrm{OH})$ side groups and the $(\mathrm{C}-\mathrm{O}-\mathrm{C})$ glycosidic bond vibration, so the solid was hemicellulose. The peak at $1640 \mathrm{~cm}^{-1}$ may be due to the bending mode of the absorbed water and some contributions from carboxylate groups $^{18}$.

The absorption bands at $1510 \mathrm{~cm}^{-1}$ and $1420 \mathrm{~cm}^{-1}$ in curve $d$ is attributed to the ester linkage of carboxylic group of the ferulic and p-coumaric acids of $\operatorname{lignin}^{19,20,21}$. This indicated that the solid was lignin.

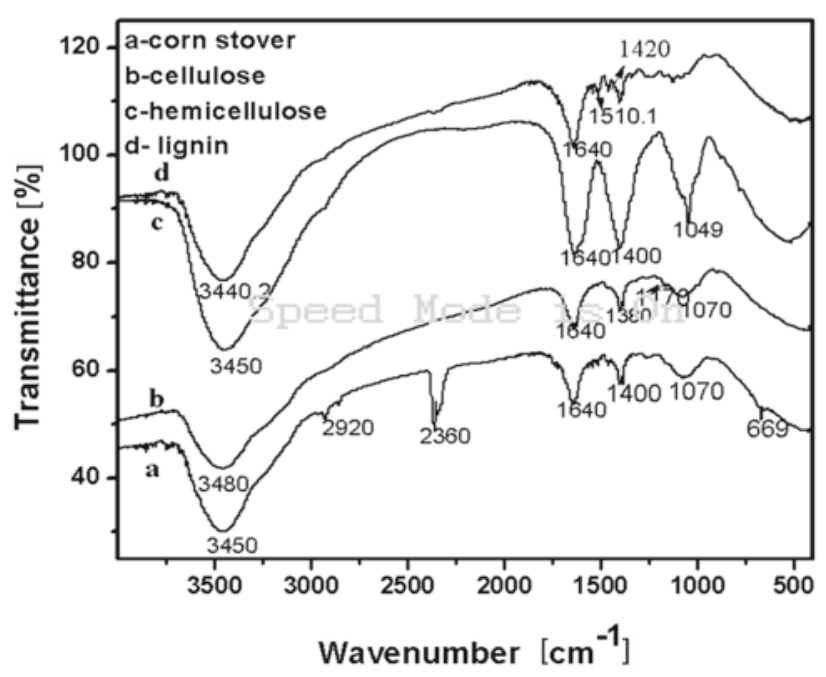

Figure 9. FT-IR spectra of lignin, (a) corn stover, (b) cellulose, (c) hemicelluloses, (d) lignin

\section{XRD analysis}

X-ray diffraction patterns of corn stover, lignin, cellulose and hemicelluloses were shown in Figure 10. As we all know, crystalline microfibrils of cellulose are surrounded by amorphous hemicellulose and the whole is embedded in the matrix of lignin. Crystalline structure 
of cellulose and hemicellulose exhibits variability in both structure and constitution. Compared curve a with $b$, it can be seen, the diffraction peaks of the residual after the treatment in alkali solvent are shaper than those of corn stover, the diffraction peaks appears at $2 \theta$ angle at ca. $16^{\circ}, 23^{\circ}$, indicating that new crystals were formed or some crystals were redirected after the treatment ${ }^{22}$, it can be explained by crystalline structure change of lignocellulose in alkali solvent could be due to more efficient removal of noncellulosic polysaccharides and dissolution of amorphous zones ${ }^{23}$. Curve $\mathrm{c}$ and $\mathrm{d}$ show the X-ray diffraction pattern of the precipitates by the acid precipitation and ethanol extraction of the liquid, the diffraction peaks of $2 \theta$ angle at ca. $32^{\circ}$ in curve $\mathrm{c}$ are shaper than in curve d, it suggested that some intra-and inter-molecular hydrogen bonding were destroyed after these treatments which led to the amorphous area to be destroyed. So molecular structure has changed and intra-molecular rearrangement reaction has occurred after treatments, the peaks at $23^{\circ}, 35^{\circ}$ in curve dindicated that hemicellulose obtained exist different forms of crystal.

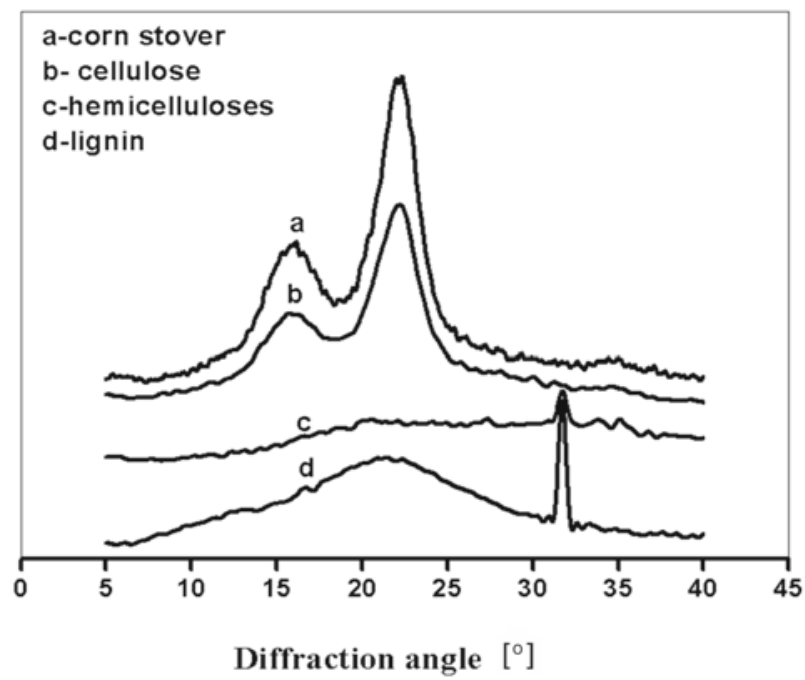

Figure 10. X-ray diffraction pattern of (a) corn stover, (b) cellulose, (c) hemicellulose (d) lignin

\section{SEM micrograph}

The SEM micrographs of corn stover, lignin, cellulose and hemicelluloses were shown in Figure 11.

It can be seen from Figure 11a, corn stover exhibited rigid and highly ordered fibrils. After treatment by alkali system (Fig. 11b), the microfibrils were separated from the initial connected structure and fully exposed. It can be stated that the surrounded structure of cellulose was destroyed and removed. The shape of the solid (Fig.11c) after acid precipitation was irregular with a few pores on the smooth surface. Concerning the hemicelluloses obtained (Fig. 11d), the hemicelluloses fractions were amorphous though its morphological characteristics were different and the polymerization degree of hemicelluloses reduced obviously. As can be shown from the picture, the separation efficiency of cellulose, hemicellulose and lignin in $\mathrm{NaOH}-\mathrm{H}_{2} \mathrm{O}_{2}$ system is high.

\section{Purification testing of components separated}

The purity of cellulose, hemicellulose, and lignin separated were determined according to the method of NREL ${ }^{11}$,
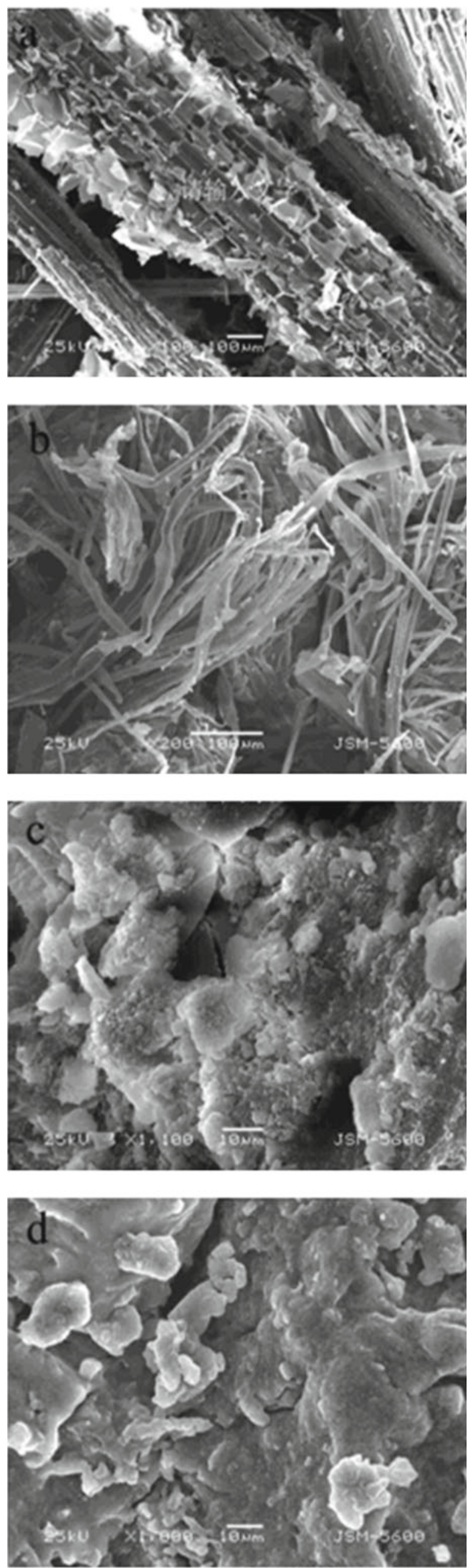

Figure 11. SEM micrograph of lignin, cellulose and hemicellulose 
the results indicate that the purity of cellulose, lignin and hemicellulose is $98.7,96.5$ and $98.7 \%$, respectively.

\section{CONCLUSIONS}

This paper proposed a new process for the dissolution and separation of corn stover in $\mathrm{NaOH}-\mathrm{H}_{2} \mathrm{O}_{2}$ system. The optimum process conditions of separation of components were determined as follows: the concertration of $\mathrm{H}_{2} \mathrm{O}_{2}$ $5.0 \%, \mathrm{pH} 11.5$, dissolution temperature $60^{\circ} \mathrm{C}$, dissolution time $3.0 \mathrm{~h}$, the ratio of liquid to solid $30 \mathrm{~mL} / \mathrm{g}$. At this conditions, the cellulose, lignin, hemicellulose recovery yield can reach to $84.2,86.6,96.7 \%$, respectively. After recycling the solvent 3 times, the lignin, cellulose and hemicellulose recovery yield was 87.6, 82.7 and 97.4\%, respectively.

\section{LITERATURE CITED}

1. Bobleter, O. (1994). Hydrothermal degration of polymers derived from plants. Prog. Polym. Sci. 19(5), 797-841. DOI: 10.1016/0079-6700(94)90033-7.

2. Pietrzak, W. \& Kawa-Rygielska, J. (2013). Utilization of spent brewer's yeast for supplementation of distillery corn mashes. Pol. J. Chem. 15(4), 102-106. DOI: 10.2478/pjct-2013-0076.

3. Stelte, W., Holm, J.K., Sanadi, A.R., Barsberg, S., Ahrenfeldt, J. \& Henriksen, U.B. (2011). A study of bonding and failure mechanisms in fuel pellets from different biomass resources. Biomass Bioenergy. 35(2), 910-918. DOI: 10.1016/j. biombioe.2010.11.003.

4. Pérez, J., Muñoz-Dorado, J., Rubia, T.D.L. \& Martinez, J. (2002). Biodegradation and biological treatments of cellulose, hemicellulose and lignin: an overview. Int. Microbiol. 5(2), 53-63. DOI 10.1007/s10123-002-0062-3.

5. García, J.C., Díaz, M., Garcia, M.T., Feria, M.J., Gómez, D.M. \& López, F. (2013). Search for optimum conditions of wheat straw hemicelluloses cold alkaline extraction process. Biochem. Eng. J. 71, 127-133. DOI: 10.1016/j.bej.2012.12.008.

6. Shi, J.B., Yang, Q.L., Lin, L. \& Zhuang, J.P. (2011). The structural changes of the bagasse hemicelluloses during the cooking process involving active oxygen and solid alkali. Carbohydr. Res. 5(359), 65-69. DOI: 10.1016/j.carres.2012.06.021.

7. Zhang, Y.Z., Fu, X.G. \& Chen, H.Z. (2011). Pretreatment based on two-step steam explosion combined with an intermediate separation of fiber cells-Optimization of fermentation of corn straw hydrolysates. Bioresour Technol. 5, 100-104. DOI: 10.1016/j.biortech.2012.07.006.

8. Kim, T.H. \& Lee, Y.Y. (2006). Fractionation of corn stover by hot-water and aqueous ammonia treatment. Bioresour Technol. 97(2), 224-232. DOI: 10.1016/j.bej.2012.12.008.

9. Sun, X.F., Xu, F., Sun, R.C., Wang, Y.X., Flowler P. \& Baird, M.S. (2004). Characteristics of degraded lignins obtained from steam exploded wheat straw. Polym. Degrade. Stabil., 86(2), 245-256. DOI: 10.1016/j.polymdegradstab.2004.05.003.

10. Toledano, A., García, A., Mondragon, I. \& Labidi, J. (2010). Lignin separation and fractionation by ultrafiltration. Sep. Purif. Technolo. 71(1), 38-43. DOI:10.1016/j. seppur.2009.10.024.

11. Pan, X.J., Sano, Y.T. \&. Ito (1999). Atmospheric acetic acid pulping of rice straw II: behavior of ash and silica in rice straw during atmospheric acetic acid pulping and bleaching. Holzforschung. 53(1), 49-55. DOI: 10.1515/HF.1999.009.

12. Doner, L.M., Kevin, B. \& Hicks (1997). Isolation of hemicellulose from corn fibre by alkaline hydrogen peroxide extraction. Cereal Chem. 74, 176-181. DIO:10.1094/ CCHEM.1997.74.2.176.

13. Dence, C.W. (1996), Chemistry of mechanical pulp bleaching. In C. W. Dence \& D. W. Reeve (Eds.), Pulp ble- aching-principle and practice (pp. 349-361), Atlanta, GA: TAPPI Press.

14. Sun, R.C., Tomkinson, J., Ma, P.L. \& Liang, S.F. (1999). Comparative study of hemicelluloses from rice straw by alkali and hydrogen peroxide treatments. Carbohydr Polym. 42(2), 111-122. DOI: 10.1016/S0144-8617(99)00136-8.

15. Liitiä, T., Maunu, S.L. \& Hortling, B. (2000),Solid State NMR Studies on Cellulose Crystallinity in Fines and Bulk Fibres Separated from Refined Kraft Pulp. Holzforschung 54(6), 618-624. DOI:10.1515/HF.2000.104.

16. Xiao, B., Sun, X.F. \& Run, R.C. (2001). Chemical, structural, and thermal charactcrizations of alkali-soluble ligins and hemicelluloses and cellulose from maize stems, ryc straw, and rice straw, Polym. Degrad. Stab. 74(2), 307-319. DOI: 10.1016/ S0141-3910(01)00163-X.

17. Sain, M. \& Panthapulakkal, S. (2006). Bioprocess preparation of wheat straw fibers and their characterization, Ind Crop Prod. 23(1), 1-8. DOI: 10.1016/j.indcrop.2005.01.006.

18. Sun, X.F., Xu, F., Sun, R.C., Fowler, P. \& Baird, M.S. (2005). Characteristics of degraded cellulose obtained from steam-exploded wheat straw, Carbohydr. Res. 340(1), 97-106. DOI: 10.1016/j.carres.2004.10.022.

19. Cherian, B.M., Pothan, L.A., Nguyen-Chung, T., Mennig, G., Kottaisamy, M. \& Thomas, S.J. (2008). A novel method for the synthesis of cellulose nanofibril whiskers from banana fibers and characterization. J. Agric. Food. Chem. 56(14), 5617-5627. DOI: $10.1021 / \mathrm{j} 8003674$.

20. Alemdar, A. \& Sain, M. (2008). Production of nanocrystalline cellulose from sugarcane bagasse. Bioresour Technol. 99, 1664-1671. DOI:10.1016/j.biortech.2007.04.029.

21. Waleed, K.E.Z. \& Maha, M.I. (2003). Synthesis and characterization of cellulose resins. Adv. Polym. Tech. 14(9), 623-631. DOI: 10.1002/pat.384.

22. Oh, S.Y., Yoo, D., Shin, Y., Kim, H.C., Kim, H.Y., Chung, Y.S., Park, W.H. \& Youke, J.H. (2005). Crystalline structure anaylsis of cellulose treated with sodium hydroxide and carbon dioxide by means of X-ray diffraction and FTIR spectroscopy, Carbohydr Res. 340(15), 2376-2391. DOI: 10.1016/j.carres.2005.08.007.

23. Kaushik, A. \& Singh, M. (2011). Isolation and characterization of cellulose nanofibrils from wheat straw using steam explosion coupled with high shear homogenization, Carbohydr Res. 346(1), 76-85. DOI: 10.1016/j.carres.2010.10.020. 